\title{
Research on the Near-net Forging Processes for the Shell Body Made by High-strength Steel
}

\author{
Taibin $\mathrm{Wu}^{1, \mathrm{a}, \mathrm{b}}$ \\ ${ }^{1}$ Research institute for new materials technology, Chongqing University of Arts and Science, \\ Chongqing 402160, China \\ a1021041243@qq.com, bwutaibin@tom.com
}

Keywords: High-strength steel, Shell body, Near-net forging, Cold ironing, Warm forging.

\begin{abstract}
According to the characteristics of the shell body and the Deformability of $30 \mathrm{CrMnSi}$, the near-net forging technique is obtained by choosing the preforming process, formulating the drawing of cold ironings and the drawing of warm forgings, designing the cold ironing die set and the warm forging die sets. It used for the shell body made by the high-strength steel and can be manufactured in high quantity production.
\end{abstract}

\section{Introduction}

The high-strength steels such as $30 \mathrm{CrMnSi}, 35 \mathrm{CrMnSi}$ and so on have high strength and the ratio of the strength to density to bear the heavy load and reduce the weight of parts made from such steels. Therefore, these steels are widely used in aeronautical engineering and aviation industry, for example the landing frame parts and the structural parts of aircraft, and the motor bodies of rackets, etc.[1].

The conventionly process was the machining process for the shell bodies made from these high-strength steels [1]. However, the high tenacity of these steels made the machining process hard and the surface stress in the machining workpiece would lead to the stress corrosion cracking. At the same time, the high consumption of the man-hours, raw and processed materials and the cutting tools would lead to the lower utilization of materials, lower productivity and highly cost of production.

With the development of the chipless working technology, the shell body with large inside diameter made from the high-strength steels is manufactured by the power spinning process. As for the shell bodies with small blind hole or the shell bodies with complex shapes, the hot die forging process is adopted [2-7]. Yet, the power spinning process is not suitable for the large volume production because of the expensive price of the power spinning machines, many times of spinning, and long production run and highly cost of production. While the hot die forging process is not fit for the mass production for the shell bodies with small blind hole or the shell bodies with complex shapes due to its high energy consumption, pollution of the environment, large machining allowance, lower productivity and highly cost of production.

So it is necessary and urgent to develop a precision forging technique for the mass production of shell bodies made from the high-strength steels with high productivity, lower cost of production.

\section{Characteristics of the Shell Body and Deformability of 30CrMnSi}

Characteristics of the Shell Body. Fig. 1 shows a shell body with blind hole. The key technical requirement include the high allowance and lower roughness of blind hole, meanwhile the defect such as crack and fold etc. must avoid in the shell body.

Deformability of 30CrMnSi. The shell body is made from the high-strength steel $30 \mathrm{CrMnSi}$. It has high strength and enough tenacity to bear heavy load. Workpiece made from 30CrMnSi would have a lower dead weight because of its high ratio of the strength to density. Consequently, there are wide-ranging application of this steel in the industries of ordnance and aerospace and so on.

$30 \mathrm{CrMnSi}$ cannot be used in forging process with large plastic deformation because of the high strength, lower plasticity and serious cold deformation strengthening [5]. 


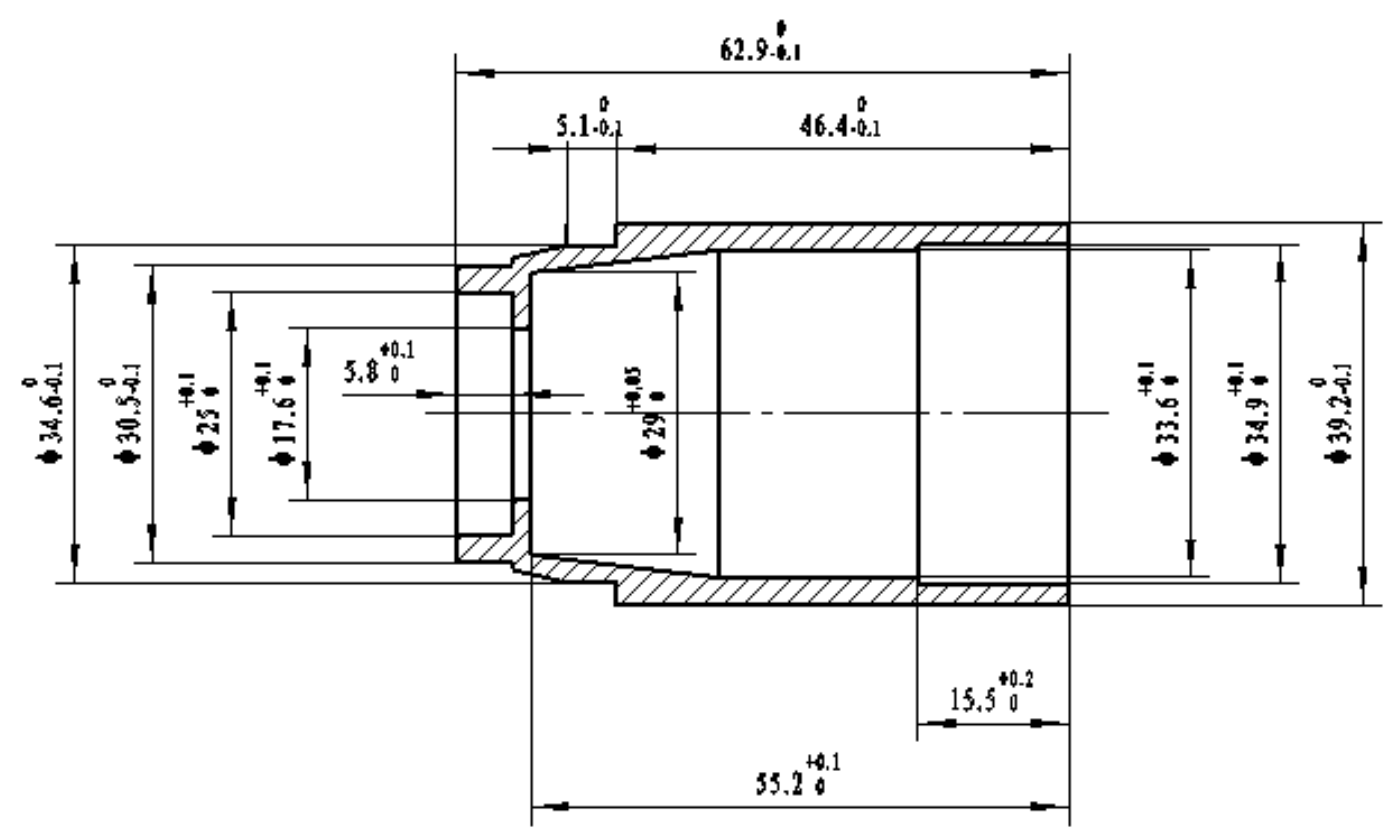

Fig. 1 The sketch of shell body.

\section{Formulating the Process Scheme}

The typical forming process for the shell body shown in Fig. 1 is as follows: preforming and ironing.

The cold ironing process must be employed to satisfy the needs of the dimensional accuracy and surface quality of shell body.

Choosing the Preforming Process. There are four machining processes to obtain the blank:

The Machining Process. The machining process will lead to large consumption of cutting tools and raw and processed materials. Additionally, the scratch mark which are caused by machining cannot be completely removed in ironing process, thus the scratch mark will influence the tenacity and security of the shell body.

Cold Forging. Cold forging with large deformation could not be employed since 30CrMnSi has poor plasticity, high strength and serious cold deformation hardening although the blind hole of blank made by cold forging have higher accuracy and surface quality.

Hot Forging. Hot forging with large deformation could be employed because $30 \mathrm{CrMnSi}$ has higher plasticity, lower strength and the effect of cold deformation hardening is very little in the forging temperature interval. By which the long die life is achieved and the blank can be easily forming, but the serious oxidation and heating loss of billet caused in the hot extrusion would influence critically the accuracy and surface quality of the blind hole of blank.

Warm Forging. Warm forging which is developed on the basis of cold forging fit to forge the medium-strength steel or high-strength steel since it avoid the disadvantages of cold forging and hot forging but possess their advantages. Besides, lower temperature as well as less oxidation and less heating loss of the billet result in high accuracy and surface quality of the blind hole of blank.

Judging from the above, it is advisable to adopt warm forging for blank.

Formulating the Near-net Forging Processes. The manufacturing processes is shown as follows:

Cropping $\rightarrow$ machining $\rightarrow$ warm forging $\rightarrow$ annealing $\rightarrow$ machining $\rightarrow$ surface lubrication treatment $\rightarrow$ cold ironing $\rightarrow$ machining

The Drawing of Cold Ironings and the Drawing of Warm Forgings. For the shell body, formulating the drawing of cold ironings should consider the follow questions:

1) For the inner hole sections for the dimensions of $\varnothing 17.6$ and $\varnothing 25$, these are very difficulty to deform, should consider the excess metal. 
2) For the outer surface sections for the dimensions of $\varnothing 30.5$ and $\varnothing 34.6$, and the section of the cone, not only these are very difficult to deform, but also the breakage always occure on the cone in cold ironing process because the thickness on the cone is very thin. Therefore, these sections should consider the excess metal.

3) The both ends of the shell body should consider the excess metal.

4) For the outer surface sections for the dimensions of $\varnothing 39.2$ should consider the excess metal.

5) For the inner hole sections for the dimensions of $\varnothing 29, \varnothing 33.6$ and $\varnothing 34.9$, and the section of the cone should deform completely, should not consider the excess metal.

The drawing of cold ironings as shown in Fig. 2.

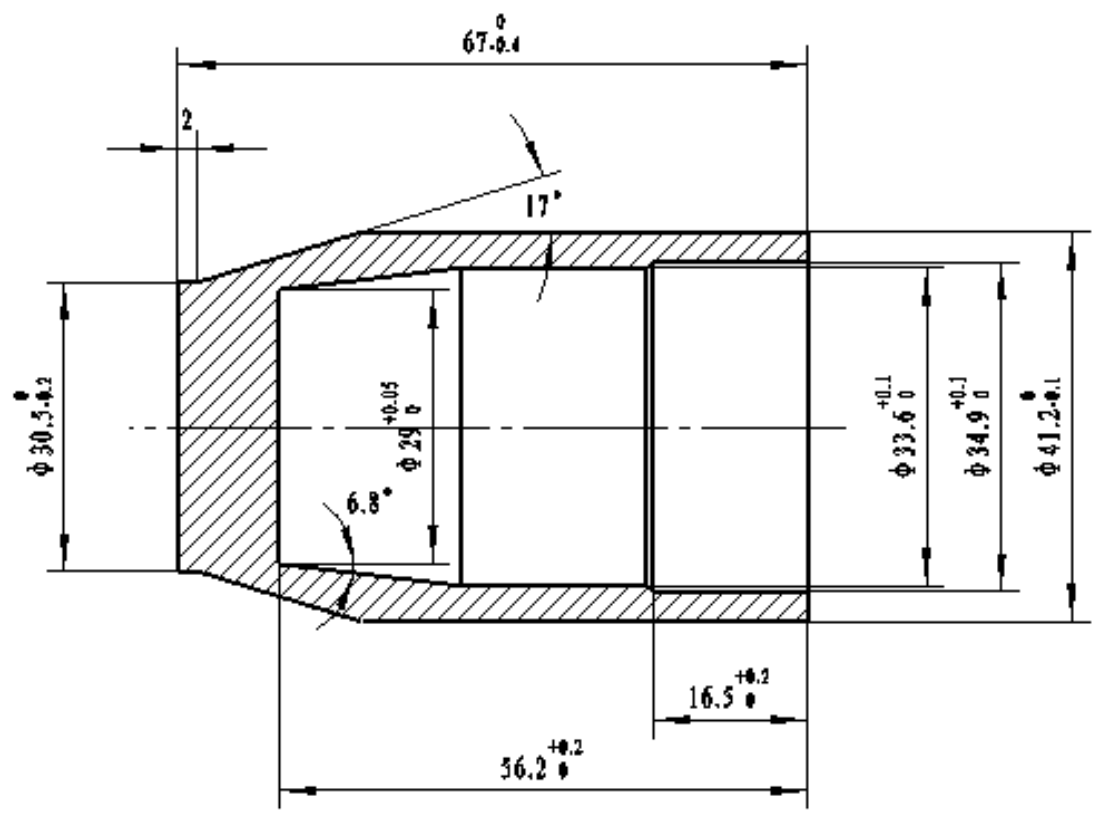

Fig. 2 The drawing of cold ironings.

For the drawing of cold ironings as shown in Fig. 2, formulating the drawing of the warm forgings should consider the follow questions:

1) The distribution of the degree of deformation.

2) The filling performance of metal in warm foring process.

3) The heating specification of warm foring.

4) The machining process after annealing.

The drawing of warm forgings as shown in Fig. 3.

\section{Near-net Forging Process}

\section{Warm Forging Process}

The Dimension of the Billet. According to the constancy of volume in forging process and the location of the billet, the shape of the billet: $\varnothing 45 \times 25$.

The Warm Forging Temperature Interval. The hot forging temperature interval of $30 \mathrm{CrMnSi}$ is $1180^{\circ} \mathrm{C} \sim 850^{\circ} \mathrm{C}$. Considering the Deformability of $30 \mathrm{CrMnSi}$ and the technical requirements of the warm forgings, the heating temperature of warm forging for $30 \mathrm{CrMnSi}$ should be $950{ }^{\circ} \mathrm{C} \pm 10^{\circ} \mathrm{C}$, the dwelling time should be 60 minutes. In this process, the initial forging temperature should be $910^{\circ} \mathrm{C}$. To prolong the service life of the die, the finish forging temperature should be controlled at above $850^{\circ} \mathrm{C}$. 


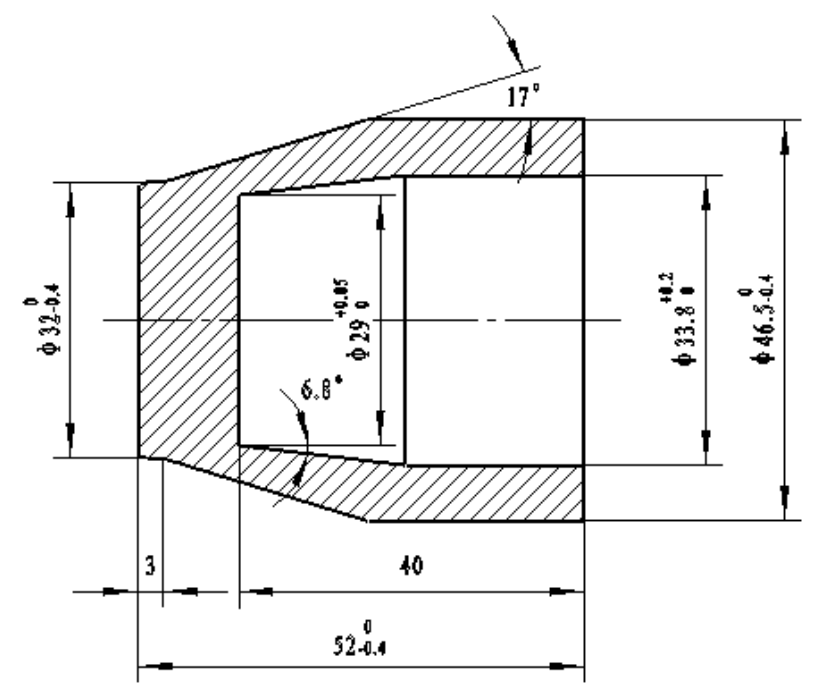

Fig. 3 The drawing of warm forgings.

Lubricant and Ways of Lubricating. There were two types of lubricant in this process:

The Oil Lubricant. Which is of well lubricant film and easy to paint and can guarantee the filling of the warm forgings. But it is not only hard to remove once adhering to the warm forgings but also pollutes the environment and working environment.

The Colloidal Graphite Mixed With Water. Which is of well lubricant film and applied to both the immersion painting and the spray painting also guarantees the filling of the warm forgings. In contrast to oil lubricant, it is easy to remove from the warm forgings and it have no effect upon the environment.

Judging by the above comparison, it is sensible to use the colloidal graphite mixed with water.

The ways of lubricating are as follows: the immersion painting is used for the punch, the spray painting is used for the lower die.

\section{Cold Ironing}

Softening Annealing Treatment of the Warm Forgings. After warm forging, the warm forgings, of which the crystal grains are different in size and the carbides are uneven distribution. Without annealing, it is extremely difficult to meet the requirements of the cold ironing process with large deformation.

In order to lower the deformation resistance, to improve the plasticity, and to get fine spherical grain structures of uniform size, the softening treatment of the warm forgings is vital. After annealing, the hardness of the warm forgings should be lower than HB180.

Lubrication for the Blank. Well purification and lubrication for the blank are essential in order to get easily the high surface quality of cold ironings. After the surface treatment, to which phosphate coating and soap treatment were applied, there is a uniform, fine and smooth coating protective covering the blank. A lubricating layer which is in well lubrication in cold ironing process has formed since the coating protective is in tight bond to the forgings surface.

\section{Design of the Die}

\section{The Characteristics of the Warm Forging Die}

The structure of warm forging die set is shown in Fig. 4. It has the following features:

1) Combined punch benefits not only longer punch life which is due to improved bearing condition which results from the elimination of stress concentration of the corner of the punch but also shorter production cycle of the punch, and the punch is easy to change.

2) Combined lower die with single shrink ring strengthen, which contributes to longer the life of the lower die. Meanwhile, the die core which is in small size results in less consumption of die material as well as easier machining and heat treatment. 
3) In order to guarantee the concentricity between the punch and die core controlled within $\pm 0.05 \mathrm{~mm}$, the four adjustable bolts was symmetrically distributed in the die holder. It can adjust the position of the lower die on the $\mathrm{X}$ axis and $\mathrm{Y}$ axis, and it is convenient to adjust the coaxiality of the punch and the die core.

Design of the die core is based on the design principles of cold extrusion combined die. The shape and size of cavity of the die core should consider the expansion caused by elastic deformation, wear and temperature increase in warm forging process and consider the forgings cooling shrinkage after warm forging, the interior diameter of the die core should be certain longer than the exterior diameter of the corresponding proportion of the warm forgings.

Design of the Die for Cold Ironing. The structure of the die set for the cold ironing is shown in Fig. 5.

The Punch. The shape and size of working portion of the punch should be identical with the shape and size of the cavity of the cold ironings. Additionally, there must be some clearance between the punch and the hole of the blank to reduce friction. Yet the gap should not be too much wide in order to avoid the breakage of cold ironings. The length of the punch has much to do with that of the cold ironings and the vacancy between the die set of the the punch and the die set of the lower die. There must be little inclination at the cylinder of the punch on account of the possibility of the stripper as well as the structure of the cold ironings. Considering stiffness of the punch, working portion of the punch should meet the requirement of the cold ironings, the other portion should be thickened but its diameter should not longer than the exterior diameter of the cold ironings to avoid collision with the lower die.

The Lower Die. Design of the lower die is on the grounds of the exterior diameter of the cold ironings. The design of shape and structure of the lower die should be on the basis of rationality of hardness of the lower die along with the economical efficiency of the cold ironing process.

In cold ironing process, the die cavity has to bear radial load, the combination die with a single shrink ring is applied to the lower die to prevent bursting of the die core in cold ironing process.

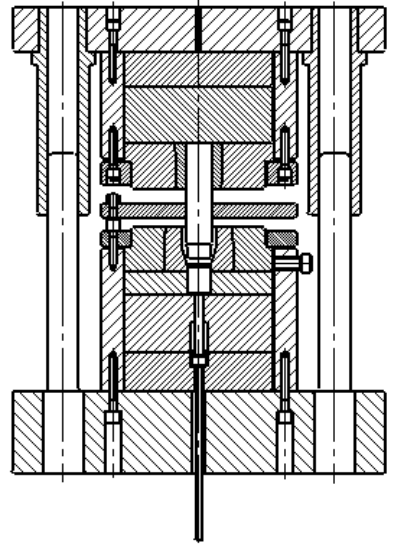

Fig. 4 The die set of warm forging.

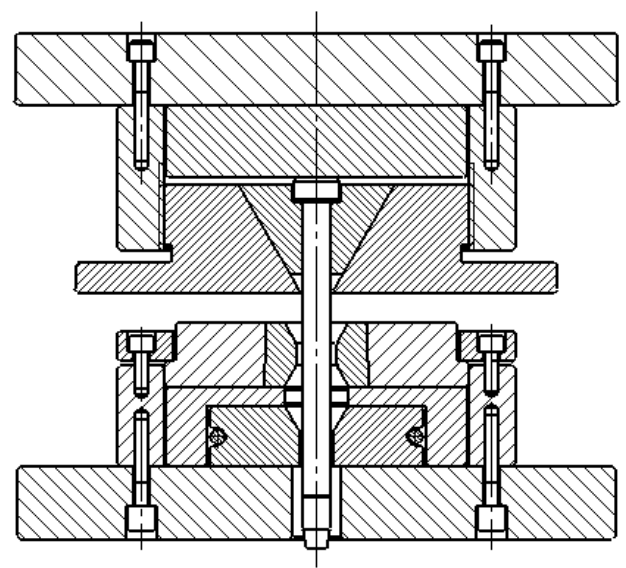

Fig. 5 The die set of cold ironing.

\section{Conclusion}

Compared with the conventional machining process, the high-strength steel shell body made by the warm forging and the cold ironing technology reaches the following technical demand:

1) The roughness of surface of the cavity of the cold ironings reaches Ra0.8 Ra1.6 $\mu \mathrm{m}$, it is a great help to eliminate the sensitivity to crack for the shell body.

2) Less thickness deviation of the shell body, only $0.15 \mathrm{~mm}$.

3) The shape and size of cavity of the cold ironings can be reached the technical demand of the shell body without subsequent machining. The outer surface of the cold ironings must be machined to reach the technical demand of the shell body, yet the machining allowance is very little.

4) The lower consumption of the raw and processed materials, the utilization of material rising from $50 \%$ to more than $90 \%$. 


\section{References}

[1] Z. Y. Zhao, Theory, Development and Application of Aeronautical High Tensile Steels, J. Mater. Eng. 2 (1991) 29-31.

[2] Z. Y. Zhou, Y. Lu and X. M. Zhao, et al. Stepped Spinning of Large-diameter Thin-wall 30CrMnSiA workpieces. J. Harbin Inst. Technol. 29(4) (1997) 107-110.

[3] C. J. Ren, Y. T. Yang And L. W. Zhang, Research on Precise Spinning Process for Abrupt Wall-thickness Cylinder. Hot Working Technol. 40(23) (2011) 112-114.

[4] C. J. Ren And L. W. Zhang, Spinning Forming Technology of 30CrMnSiA Thin-wall and Inclined Irregular parts, Hot Working Technol. 34(7) (2005) 56-57.

[5] S. W. Wang and S. R. Wei, Hot Forging of $30 \mathrm{CrMnSi}$ aAlloy Constructional Steel Cylindrical Shell Blank, J. Netshape Forming Eng. 4(5) (2012) 48-50.

[6] L. Y. Wang, G. W. Zhao and B. S. Gao, et al. Spinning Process Research of 30CrMnSiA Steel Shell with Thin-walled Variable Cross-section, J. Netshape Forming Eng. 5(3) (2012) 86-88.

[7] Y. G. Yang, L. W. Zhang and D. Han, Research on Stagger Spinning Forming Process of 30 CrMnSiA Steel Feathered Tube, Met. Forming Technol. 22(2) (2004) 64-66. 